\title{
ISOLATION OF AEROBIC BACTERIA IN COWS WITH SUBCLINICAL MASTITIS IN TURKEY AND EVALUATION OF THEIR ANTIMICROBIAL SUSPECTIBILITY
}

\author{
SERPILL KAHYA DEMİRBILEK \\ Uludağ Üniversity Faculty of Veterinary Medicine Microbiology Department, Bursa, \\ 16059, Turkey
}

Received: 1 October 2020; Accepted: 21 October 2020

\begin{abstract}
This study was conducted to determine the presence and prevalence of aerobic bacteria in cattle with subclinical mastitis (SCM) and evaluation of their antimicrobial suspectibility. In this study, a total of 394 unmedicated cows from 13 dairy farms were randomly selected and screened for SCM using California Mastitis test (CMT) were used. Overall, 294 agents were isolated and identified from milk samples by classic bacteriological methods. Isolated bacteria were tested by Kirby-Bauer antibiogram disc diffusion test to determinate antimicrobial resistance profile. A total of 294 (74.6\%) agents were isolated from 394 milk samples; $100(25.4 \%)$ of the milk samples, neither bacteria nor yeast were isolated. Staphylococcus spp and Streptococcus spp. were the most frequently isolated bacteria, found in $106(36 \%), 90(31 \%)$ of the samples, respectively. Among the samples, 68 (23.1\%) were positive for S. aureus, 34 (11.5\%) for Coagulase negative Staphylococcus, 34 (11.5\%) for Escherichia coli, 22 (7.5\%) for Bacillus spp., 18 (6.1\%) for Corynebacterium spp., 8 (2.7\%) Corynebacterium bovis and Pseudomonas aeruginosa, 6 (2\%) for Streptococcus dysagalactiae sp. dysagalactiae, 4 (1.3\%) for Staphylococcus chromogenes, Klebsiella pneumonia, Actinomyces spp. The most sensitive 3 antibiotic were Amicasin (78\%), Tobramicin (73\%) and Gentamicin (72\%) against isolated bacteria. In conclusion, because of a high percentage isolation of Staphylococcus and Streptoccocus from cows with subclinical mastitis, we are especially struggle for this two bacteria to prevent cows from mastitis and it is important to test the antimicrobial sensitivity of aetiological agents of mastitis before treatment so as to prevent the development of antibiotic resistance in bacteria.
\end{abstract}

Keywords: Antimicrobial Suspectibility Testing, Bacteria, Cow, Mastitis, Subclinic

\section{INTRODUCTION}

Bovine mastitis is a multi-ecological and commonly prevalent most costly

Corresponding author: Serpil Kahya Demirbilek E-mail address: serpilkahya@uludag.edu.tr Present address: Uludağ Üniversity Faculty of Veterinary Medicine Microbiology Department, Bursa, 16059, Turkey complex disease in dairy industries. Different studies have shown mastitis to be one of the most costly diseases of the dairy industry worldwide. Clinical mastitis $(\mathrm{CM})$ is characterized by visible changes in milk that may be associated with inflammation signs of the udder or the cow. Subclinical mastitis (SCM) is asymptomatic, therefore produced milk appears to be normal, causes higher economic losses to farmers. According to Shearer and Harris (2003) subclinical mastitis is important 
due to the fact that it is 15 to 40 times more prevalent than the clinical form, it usually precedes the clinical form, is of longer duration, difficult to detect, adversely affects milk quality and production, and constitutes a reservoir of microorganisms that lead to infection of other animals within the herd. While it is easy to detected CM (seeing clotted milk), SCM can only be demonstrated using various tests such as California Mastitis Test (CMT). CMT has been recognized as a highly sensitive test to detect bovine subclinical mastitis. In order to identify mastitis causing microorganisms, the microbial culture procedures still are the gold standard (Khan and Khan, 2006).

More than 135 types of microbes were reported to be previously implicated in bovine mastitis cases, but the most associated were staphylococci, streptococci, and Gram negative bacteria (Bradley, 2002). The composition of many strains of bacteria associated with mastitis has changed with time. Mastitis is divided two forms according to pathogens. Contagious mastitis is the "cow-associated" form where infected cows are the reservoirs for bacteria and spread occurs cow to cow at milking time. As the name suggests, environmental mastitis comes from the cow's world. Mastitis agents that are spread from one cattle to another are referred to as contagious pathogens while those that are present in the herd's vicinities are called environmental pathogens. The most common mastitis pathogens are found either in the udder as contagious pathogens or in the animal surroundings such as bedding and manure soil as environmental pathogens. Among the contagious pathogens, the most common are Staphylococcus aureus (S. aureus) and Streptococcus agalactiae (S. agalactiae). These are spread from infected to clean udders during the milking process thorough contaminated milker's hands, cloth towels used to wash or dry udder of more than one animal and possibly by flies. Among environmental pathogens, the most common bacteria are Streptococcus uberis (S. uberis), Streptococcus dysagalactiae (S. dysagalactiae), coliforms such as Escherichia coli (E. coli) and Klebsiella spp.
Transmission of these pathogens may occur during milking but primarily between milkings (Bradley, 2002).

Antimicrobial agents have been primarily administered to treat mastitis. However, antimicrobial resistance is an increasing global health threat, potentially affecting the effective treatment of bacterial infections. Therefore, clinical veterinarians should prudently use antimicrobials and should select antimicrobials expected to display a response on the basis of bacteriological analysis and the clinical conditions of diseased animals. However, clinical treatments for mastitis are often ineffective and cure rates are poor. It is important to identify mastitis cases in which antimicrobial treatment is ineffective before antimicrobial administration to reduce antimicrobial agent use (Harini and Sumathi, 2011).

Several studies have demonstrated the importance of farmer's attitude towards mastitis and mastitis management and investigated potential intervention and communication strategies towards these subjects. A key strategy is to identify and implement herd specific measures to improve udder health in dairy herds. Also, farmers have different perception so fodder health problems which play an important role when designing effective intervention programs. Attempting to improve udder health may, however, also lead to an increased number of antimicrobial treatments. Insights in dairy farmers'knowledge, attitude and practices towards the lactational use of intramammary antimicrobials is therefore pivotal to reach this goal. Moreover, the heterogeneous population of dairy farmers likely has different needs and characteristics (Sumon $e t$ al., 2017).

Antimicrobial resistance (AMR) arises when the pathogens are capable of overcoming the impact of antimicrobials which were 
efficient previously. In Turkey AMR remains a substantial threat in the dairy industry. Subclinical mastitis goes without diagnosis. So, this study was undertaken to find out the prevalence of SCM and to assess the antibiotic sensitivity pattern of the causative organism in Turkey.

\section{MATERIALS AND METHODS}

\section{Sampling method}

The study was carried out on 394 lactating cross-breed apparently healthy lactating cows in Turkey. The basis for sampling was the hygiene. Prior to milk collection for mastitis screening, clinical examination were performed on the every lactating cow. Through palpation of the udder to detect any fibrosis, swelling and other clinical signs were performed. Watery milk, milk with pus or clots and blind quarters were also examined. Identification of at least one of these signs was enough to consider the mammary quarter as positive to $\mathrm{CM}$ and was excluded from the study. That is, the samples were taken shortly prior to milking and only cows expressing no clinical signs of mastitis were sampled. Composite milk samples from CMT positive cows were aseptically collected directly from quarters into aseptic tubes and taken to the laboratory for bacteriological analysis to identify SCM causative microorganisms. Prior to sampling, the first streams of milk were discarded, and teat ends were disinfected with cotton swabs soaked in $70 \%$ alcohol and allowed to dry.

\section{California mastitis test (CMT)}

Subclinical mastitis prevalence was obtained by the use of CMT which was conducted using scores from 0 to 4 from modified Scandinavian scoring system, where 0 is negative result (no gel formation), 1 is traceable (possible infection), and 2 or 3 indicates a positive result and 4 has the thickest gel formation. A sample was defined as positive to SCM when one or more quarters with $\mathrm{CMT} \geq 2+$ were detected.

After confirming SCM by CMT, the udder and teats were cleaned with water and wiped using sterile towels. The teat orifice and the skin around the teat were sprayed with $70 \%$ alcohol and dried off with sterile towels.

\section{Bacteriological assays}

Milk samples were bacteriologically examined according to the procedure previously described (Kenar et al, 2019). After reaching to the laboratory milk samples were aseptically removed from the cooler box for examination. $0.01 \mathrm{ml}$ of each milk sample was cultured separately onto Eosine Methylene Blue agar, MacConcey's agar and sheep Blood agar plates by streaking method. Inoculated plates were then incubated aerobically at $37{ }^{\circ} \mathrm{C}$ for 24 48 hours. After 24 hours, primary bacteriological identification was made based on colony morphology, color and hemolytic characteristics, these were considered as pure or individual cultures. After primary culture readings, pure cultures were prepared thorough subculturing and incubation. The purified isolates were then subjected to Gram staining and further biochemical testing. The staining and cellular morphological features of organisms were ascertained by microscopic examination of Gram stained smears. Staphylococci were identified based on catalase test and tube coagulase test. Streptococci were identified based on catalase and Christie, Atkins and MunchPeterson (CAMP) test. Gram negative isolates were identified based on growth characteristics on MacConcey agar and reactions to strip oxidase test, catalase test, Triple Sugar Iron (TSI) agar and IMVIC tests (Indole, Methyl-Red, Vogas Proskaur and Citrate utilisation).

\section{Antimicrobial susceptibility testing}

Phenotypic assessment of antimicrobial susceptibility was achieved by KirbyBauer's disc diffusion test used in line with 
the Clinical Laboratory and Standards Institute (CLSI) guidelines. The 10 tested antimicrobial agents and their corresponding concentrations were as follows: amoxicillinclavulanic acid $(30 \mu \mathrm{g})$, gentamycin (120 $\mu \mathrm{g})$ ampicillin/cloxacillin $(25 \mu \mathrm{g})$, tobramycin $(10 \mu \mathrm{g})$, amikacin $(30 \mu \mathrm{g})$, enrofloxacin $(5 \mu \mathrm{g})$, chloramphenicol (30 $\mu \mathrm{g}), \quad$ doxycycline $\quad(30 \quad \mu \mathrm{g})$, lincomycin/spectinomycin $(9 / 100 \mu \mathrm{g})$, and polymyxin $\mathrm{B} \quad(10 \mu \mathrm{g})$. The reference bacterial strains E. coli (ATCC 25922) and $S$. aureus (ATCC 25923) were used as quality control strains following the CLSI recommendations.

\section{RESULTS}

\section{Distribution of bacterial pathogens}

The microorganisms identified in this study and antibiogram test results are shown in Table 1-2. A total of 294 (74.6\%) agents were isolated from 394 milk samples; 100 $(25.4 \%)$ of the milk samples, neither bacteria nor yeast were isolated. Staphylococcus spp. and Streptococcus spp. were the most frequently isolated bacteria, found in 106 $(36 \%), \quad 90 \quad(35 \%)$ of the samples, respectively. Among the samples, 68 (23.1\%) were positive for $S$. aureus, 34 $(\% 11,5)$ for Coagulase negative Staphylococcus, 34 (11.5\%) for E. coli, 22 (7.5\%) for Bacillus spp., $18(6.1 \%)$ for Corynebacterium spp., $8 \quad(2.7 \%)$ for Corynebacterium bovis (C. bovis) and Pseudomonas aeroginosa ( $P$. aeroginosa), 6 (2\%) for $S$. dysagalactiae sp. dysagalaksiae, $4(1.3 \%)$ for Staphylococcus chromogenes,
Klebsiella pneumonia, Actinomyces spp.

\section{Antimicrobial resistance profile}

Antibiotic susceptibility testing was carried out for 10 different antibiotics. The antimicrobial resistance profile of the isolates tested is shown in Table 2. The resistance levels of the antimicrobials vary among the mastitis isolates tested. For the overall isolates, the highest resistance levels observed were 59\% for Doxycycline, 52\% for Lincomycin/Spectinomycin, $50 \%$ for Chloramphenicol and $46 \%$ for Polymyxin B. This is followed by $44 \%$ for Amoxicillin, $44 \%$ for Enrofloxacin, $42 \%$ for Ampicillin/cloxacillin, 28\% for Gentamycin and $27 \%$ for Tobramycin. The least resistance levels were observed for Amikacin with $22 \%$.

For individual isolates, relatively high levels of resistance were demonstrated against the tested antibiotics. However, some isolates have shown quite high level of resistance against few antibiotics. It can be observed that resistance profile of Streptococcus spp. isolates against Lincomycin/Spectinomycin and Polymyxin B were $63 \%$ and $61 \%$ respectively while that of Staphylococcus aureus against chloramphenicol and Doxycycline were 100\%. Coagulase negative Staphylococcus isolates resistant against Doxycycline and Amoxicillin 79\% and $68 \%$, respectively. For E. coli isolates, $85 \%$ and $68 \%$ have shown resistance to Doxycycline and chloramphenicol respectively. 
Table 1: Isolated bacteria from milk from cow with subclinical mastitis.

\begin{tabular}{|c|c|c|}
\hline Isolated bacteria & $\begin{array}{l}\text { Number of } \\
\text { isolation }\end{array}$ & $\begin{array}{c}\text { Rate of isolation } \\
\%\end{array}$ \\
\hline Streptococcus spp. & 84 & 28.5 \\
\hline Staphylococcus aureus & 68 & 23.1 \\
\hline Coagulase negative staphylococcus & 34 & 11.5 \\
\hline Esherichia coli & 34 & 11.5 \\
\hline Bacillus spp. & 22 & 7.48 \\
\hline Corynebacterium spp. & 18 & 6.1 \\
\hline Corynebacterium bovis & 8 & 2.7 \\
\hline Pseudomonas aeruginosa & 8 & 2.7 \\
\hline S. dysagalactia sp. dysagalaksia & 6 & 2 \\
\hline Staphylococcus chromogenes & 4 & 1.3 \\
\hline Klebsiella pneumonia & 4 & 1.3 \\
\hline Actinomyces spp. & 4 & 1.3 \\
\hline
\end{tabular}


Table 2: Antibiotic resistance (\%) of microbial agents isolated from dogs with bacterial otitis extrena

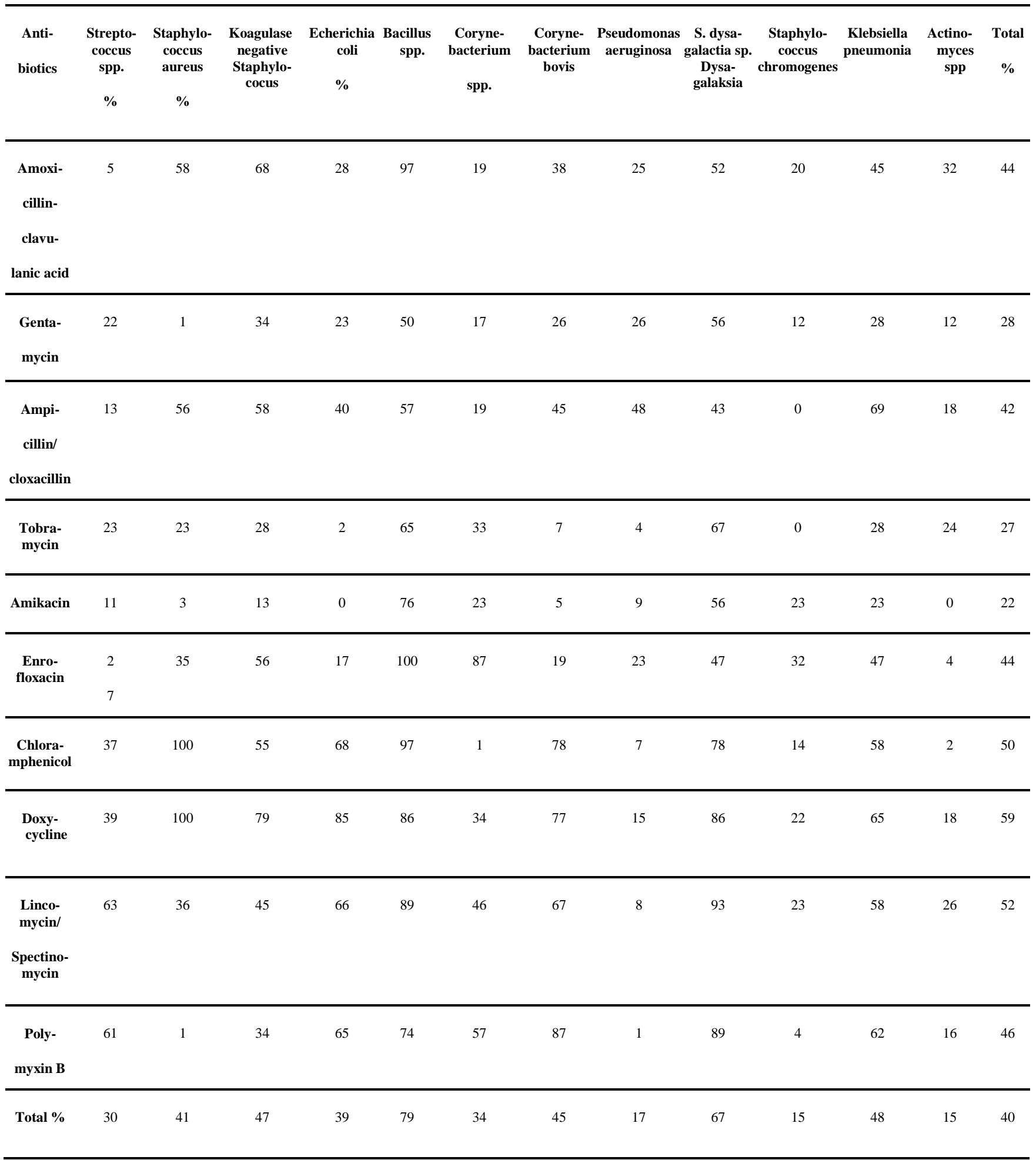




\section{DISCUSSION}

Composite CMT results, culture, and readings of biochemical tests were evaluated to determine the prevalence of SCM and related causative bacteria. The prevalence of SCM based on bacteriological culture in this study is recorded as $74.6 \%$. The results from this study show a high prevalence of SCM. A possible explanation for this finding could be that most farmers in Turkey do not practice proper farming management and screen for mastitis at earlier stage. The current findings corroborate with those reported in recent studies (Çokal and Konuş, 2012; Macun et al., 2011, Yeşilmen et al., 2012) and in the Turkey.

$S$. aureus is the predominant of all the staphylococcal species isolated in this study. Similar results have been reported previously from (Ali et al., 2020, Çokal and Konuş 2012, Harini et al., 2011, Macun et al., 2011, Yeşilman et al., 2012) although the prevalence among these studies varies. Is one of the main pathogens for contagious mastitis, and it is believed to be transmitted during milking. Lack of dry cow therapy in dairy herds could be responsible for continuous pathogens like $S$. aureus and $S$. agalactiae.

Different studies have shown that SCM is mainly caused by Coagulase negative Staphylococci (CNS), S. aureus, $S$. agalactiae other Streptococcus species, and coliforms (Ali et al., 2020, Harini et al., 2011, Yeşilman et al., 2012). Mpatswenumugabo et al., (2017) from a total of 62 composite SCM positive samples cultured, 68 bacterial isolates were identified. They found that the most predominant bacteria were CNS at $51.5 \%$ (35/68) followed by $S$. aureus at $20.6 \%$ (14/68) other Streptococcus species at $10.3 \%$ (7/68), Bacillus spp. at $10.3 \%$ (7/68), and S. agalactiae at $5.8 \%(4 / 68)$ and the least was E. coli at $1.5 \%(1 / 68)$.
Study conducted in Bangladesh by Siddiki et al. (2019) used a total of 539 quarter milk samples, collected from lactating cows with subclinical, acute and chronic mastitis. The Staphylococcus spp. was recorded as major pathogen for all the subclinical (42.5\%), acute $(45.71 \%)$ and chronic (41.67\%) mastitis case. The highest sensitivity (up to $\% 100$ ) was recorded with gentamicin, ciprofloxacin, oxytetracycline and enrofloxacine against all the tested four organisms isolated from cases. Antibiotic resistance was highly prevalent, especially streptomycin (70-100\%), amoxacillin (30$100 \%)$ and ampicillin (0-100\%) against the four isolated bacteria of three different types of mastitis.

Harini $\mathrm{H}$ et al. (2011) were undertaken to find out the incidence of subclinical mastitis and to assess the antibiotic sensitivity pattern of causative organisms in lactating cows. The predominant bacterial isolates recovered S. aureus (58\%) and E. coli (23.5\%) followed by $S$. epidermidis (8\%), Streptococcus sp. (5.5\%), Klebsiella sp. (3\%), and Bacillus sp. (2\%). The in vitro antibiogram studies of bacterial isolates revealed higher sensitivity for ciprofloxacin $(89 \%)$, ofloxacin $(85 \%)$, enrofloxacin $(82 \%)$, gentamicin $(80 \%)$ and chloramphenicol $(75 \%)$ resistant to colistin, neomycin, streptomycin, penicillin and tetracycline.

Non-aureus staphylococci (NAS) are diverse set of about 50 bacterial species of which 20 are commonly associated with subclinical mastitis. These group of bacteria are often found on teat apices of lactating dairy cows and it has been suggested that the colonization of the teat apex may serves as reservoir for NAS species causing intramamarian infection (Traversari et al., 2019). This study is in adversity with many studies where the trend shows the dominance of NAS group of bacteria in association with subclinical mastitis. NAS has been identified as the most common 
pathogens associated with subclinical mastitis in countries like, Kenya, Turkey, Malaysia (Mpatswenumugabo et al., 2017, Kaynarca, Ali Bashir et al., 2020 and Türkyılmaz 2010). For example; Ali Bashir et al., (2020) collected a total of 1945 quarter samples from 517 cows across 33 dairy herds were used. The most prevalent isolates identified were non-aureus staphylococci $39.5 \%, S$. aureus $13.1 \%, K$. pneumoniae $6.5 \%, S$. agalactiae $4.8 \%$ and $S$. uberis $4.3 \%$. Resistance profile of $K$. pneumoniae isolates against ampicillin and penicillin $\mathrm{G}$ were $70.4 \%$ and $88.9 \%$ respectively while that Actinobacter spp against chloramphenicol and streptomycin were $71.4 \%$ and $35.7 \%$ respectively. For $S$. uberis isolates, $66.7 \%$ and $73.3 \%$ have shown resistance to tetracycline and streptomycin respectively.

Streptococcus spp. is the second predominant $90 \quad(31 \%)$ of all the staphylococcal species isolated in this study. Environmental streptococci are frequently isolated from bovine mastitis in dairy cows. A number of species of streptococcal bacteria may infect the bovine mammary gland. The most contagious species, particularly $S$. agalactiae, have become less significant over the last 50 years as more hygienic methods of milk production, application of better risk management, and the development of therapeutic methods have been adopted.

Enterobacter spp. has been reported from previous studies (Öztürk et al., 2019, Sumon et al., 2017) and are important agents of environmental intra-mammary infection and are mostly sourced from farm manure, bedding and soil (Swartz and Christina 2016). Özave1 et al. (2017) found that in isolated milk samples (174) with bacterial growth, Gram positive (63) and Gram negative (111) microorganisms were respectively isolated at $36.21 \%$ and $63.79 \%$. A total of 238 bovine milk samples with mastitis were used and the isolated agents were identified as Aeromonas hydrophila 30
(17.24\%), Citrobacter diversus 4 (2.29\%), Citrobacter freundii 2 (1.14\%), Corynebacterium sp. 24 (13.79\%), E. coli 18 (10.34\%), Enterobacter cloacae 2 (1.14\%), Flavobacter sp. 3 (1.72\%), Lactobacillus sp. 21 (12.06\%), Pasteurella pneumonia 2 (1.14\%), Plesiomonas shigelloides 11 (6.32\%), Providencia 2 (1.14\%), Salmonella sp. 2 (1.14\%), Serratia liquefacians 2 (1.14\%), Shigella sp. 18 (10.34\%), Vibrio cholera 6 (3.45\%), Yersinia enterocolitica 1 (0.57\%), coagulase-negative Staphylococcus (CNS) 18 (10.34\%), S. aureus 8 (4.59\%). Antibiotic resistance was evaluated in all isolated pathogens and the highest resistance was observed against erythromycin (63/174, $36.2 \%)$ followed by penicillin $\mathrm{G}(53 / 174$, $30.45 \%)$, Amoxicillin (38/174, 21.83\%).

Kenar et al. (2019) identified 11 characterized Gram (+) organisms from 61 milk samples of cattle. In addition 50 isolates of Gram (-) fermenting and nonfermenting Burkholdria and B. pseudomallei were screened by Gram stain. Out of the 61 samples were investigated, S. aureus, $S$. heamolyticus, E. coli, and S. epidermidis were the most emerging cattle mastitis. The current study shows that E. coli and Klebsiella spp. seem to be resistant to Amoxycillin-Clavulanic Acid $(76 \%$ and $34 \%$ ) which is slightly high than reports done before. The prevalence of $E$. coli was also lower.

Antibiotic suspectibility testing was carried out on selected most prevalent pathogens associated with bovine mastitis isolates from studied farms. Overall in this study especially doxycycline (59\%), Lincomycin/spectinomycin (52\%) and Chloramphenicol (50\%) resistance was observed.

\section{CONCLUSION}

The proper management and udder health practices, inadequate milking procedures observed by the farmers and milkers, would expose the cows to SCM caused by 
environmental and contagious bacteria during milking by miller's hand, as was mostly found in this study. On the other hand, nonuse of teat dips and other mastitis control techniques due to lack of knowledge should have greatly contributed to the high prevalence of SCM in there.

Farmers in the study area, therefore, need to be educated and encouraged to practice good farming, animal health management practices, and milking practices at all times, this will reduce udder contamination and subsequent SCM or CM. Adequate proper housing with sanitation, regular screening for early detection, and appropriate treatment of subclinical cases, dry cow therapy and application of pre-post dipping practices are also highly recommended.

\section{REFERENCES}

Bashir, A. and Zunita, Z. (2020): Prevalence and antimicrobial resistance profiles of bacterial isolates associated with intramamary infections in Malaysian dairy herds. Research Square, in press. DOI: 10.21203/rs.2.22292/v1

Bradley, A.J. (2002): Bovine mastitis: An evolving disease. The Veterinary Journal, 164(1): 116-128.

Çokal, Y. and Konuş, R. (2012): Subklinik mastitisli ineklerin sütlerinden aerobik bakterilerin izolasyonu. Balıkesir Sağlık bilimleri dergisi, 1(2): 65-69.

Harini, H. and Sumathi, B.R. (2011): Screening of bovine milk samples for sub-clinical mastitis and antibiogram of bacterial isolates. Vet World, 4(8), 358-359.

Kenar, B.; Aksoy, A. and Köse, Z. (2019): The new mastitis agents emerged in cattle in Turkey and an investigation of their antimicrobial susceptibility. Kocatepe Veterinary Journal, 12(4): 400-406.

Khan, M.Z. and Khan, A. (2006): Basic facts of mastitis in dairy animals: A review. Pakistan Veterinary Journal, 26(4): 204-208.

Macun, H.C.; Yă̆cl, I.P.R.; Ünal, N.;
Kalender, H.; Sakarya, F. and Yıldırım, M. (2011): Kirıkkale'de belirlenen subklinik mastitisli ineklerde etken izolasyonu ve antibiyotik direnç durumu. Erciyes Universitesi Veteriner Fakültesi Dergisi, 8(2): 83-89.

Mpatswenumugabo, J.P.; Bebora, L.C.; Gitao, G.C.; Mobegi, V.A.; Iraguha, B.; Kamana, O. and Shumbusho, B. (2017): Prevalence of subclinical mastitis and distribution of pathogens in dairy farms of Rubavu and Nyabihu districts, Rwanda. Journal of Veterinary Medicine, 1-8.

Özavcl, V.; Parın, U.; Yüksel, H.T. and Kirkan, S. (2017): Identification of pathogen bacteria from bovine mastitis in Yozgat province and determination of antimicrobial suspectibility. Animal Health, Production and Hygine, 6(1), 454-458.

Shearer, J.K. and Harris, B. (2003): Mastitis in dairy goats. Anim Sci Dept Florida Coop Ext Serv Inst Food Agri Sci; Univ Fl Gainesville, USA. pp: 1-6.

Siddiki, S.H.M.F.; Samad, M.A.; Saha, S.; Badiuzzaman, M. and Islam, M.T. (2019): Comparision of bacterial pathogens associated with different types of bovive mastitis and their antibiotic resistance status in Bangladesh. J Vet Med OH Res, 1(1): 17-27.

Sumon, S.; Ehsan, M. and Islam, M. (2017): Subclinical mastitis in dairy cows: somatic cell counts and associated bacteria in Mymensingh, Bangladesh. J Bangladesh Agril Univ, 15(2): 266271.

Swartz, T. and Christina, S.P. (2016): Bacillus spp.: A Practical Summary for Controlling Mastitis. Virginia Tech. Virginia University, pp.1-2.

Traversari, J.; Borne, V.D.; Dolder, B.H.P.; Thomann, $C$.; Perreten, $V$. and Bodmer, M. (2019): Non-aureus staphylococci species in the teat canal and milk in four commercial swiss dairy herds. Frontiers in Veterinary Science, 6, 11-14. 
